\title{
ARTICLE
}

\section{Challenges and Innovative Technologies On Fuel Handling Systems for Future Sodium-Cooled Fast Reactors}

\author{
Mathieu CHASSIGNET ${ }^{1, *}$, Sebastien DUMAS ${ }^{1}$, Christophe PENIGOT ${ }^{1}$, \\ Gérard PRELE ${ }^{2}$, Alain CAPITAINE ${ }^{2}$, Gilles RODRIGUEZ ${ }^{3}$, \\ Emmanuel SANSEIGNE ${ }^{3}$ and François BEAUCHAMP ${ }^{3}$ \\ ${ }^{1}$ AREVA/NP, 10 Rue Juliette Récamier, 69003 Lyon, France \\ ${ }^{2}$ EDF/SEPTEN, 12-14 Avenue Dutriévoz, 69628 Villeurbanne CEDEX, France \\ ${ }^{3}$ CEA/CADARACHE, DEN/DTN, 13108 Saint Paul lez Durance, France \\ (Received August 17, 2010 and accepted in revised form October 14, 2010)
}

\begin{abstract}
The reactor refuelling system provides the means of transporting, storing, and handling reactor core subassemblies. The system consists of the facilities and equipment needed to accomplish the scheduled refuelling operations. The choice of a FHS impacts directly on the general design of the reactor vessel (primary vessel, storage, and final cooling before going to reprocessing), its construction cost, and its availability factor. Fuel handling design must take into account various items and in particular operating strategies such as core design and management and core configuration. Moreover, the FHS will have to cope with safety assessments: a permanent cooling strategy to prevent fuel clad rupture, plus provisions to handle short-cooled fuel and criteria to ensure safety during handling. In addition, the handling and elimination of residual sodium must be investigated; it implies specific cleaning treatment to prevent chemical risks such as corrosion or excess hydrogen production. The objective of this study is to identify the challenges of a SFR fuel handling system. It will then present the range of technical options incorporating innovative technologies under development to answer the GENERATION IV SFR requirements.
\end{abstract}

KEYWORDS: refueling, fuel handling systems, availability, pantograph, external storage, flask

\section{Introduction}

CEA, AREVA, and EDF have an extensive experience and significant expertise in sodium-cooled fast reactors over the past 40 years of $R \& D$ and feedback experiments. ${ }^{1)}$ Some improvements are needed on the SFR to meet the GEN IV goals, and in particular the reduction of investment and operating costs: the fuel handling system (FHS) can be considered as an essential step in the reactor design. The reactor refuelling system provides the means of transporting, storing, and handling reactor core subassemblies. The system consists of the facilities and equipment needed to accomplish the scheduled refuelling operations. The choice of a FHS impacts directly on the general design of the reactor vessel (primary vessel, storage, and final cooling before going to reprocessing), its construction cost, and availability factor. The fuel handling design must take into account various issues particularly operating strategies such as core design and management and core configuration. Moreover, the FHS will have to cope with safety assessment: a permanent cooling strategy to prevent fuel breakage, plus the

*Corresponding author, E-mail: Mathieu.chassignet@areva.com (C)Atomic Energy Society of Japan handling and elimination of residual sodium which implies specific cleaning treatment to prevent chemical risks such as corrosion or excess hydrogen production.

AREVA in collaboration with CEA and EDF is involved in a substantial effort in FHS providing both significant expertise and original works, with assessment of designs in the framework of option choice and technical and economical assessments. The objective of this study is to provide a brief description of constraints and objectives for French studies on fuel handling systems, with also foreseen innovative options for a future fuel handling route.

\section{General Description of a Fuel Handling Route in a SFR}

\section{(Please refer to Figs. 1-4)}

The reactor refuelling system provides the means of transporting, storing, and handling reactor core subassemblies, including fuel, blanket, control, and shielding elements. The system consists of the facilities and equipment needed to accomplish the scheduled refuelling operations.

The tasks that have to fulfill a FHS are the following (including the loading and unloading of fuel assembly (FA)): - Arrival of fresh assembly (1), 


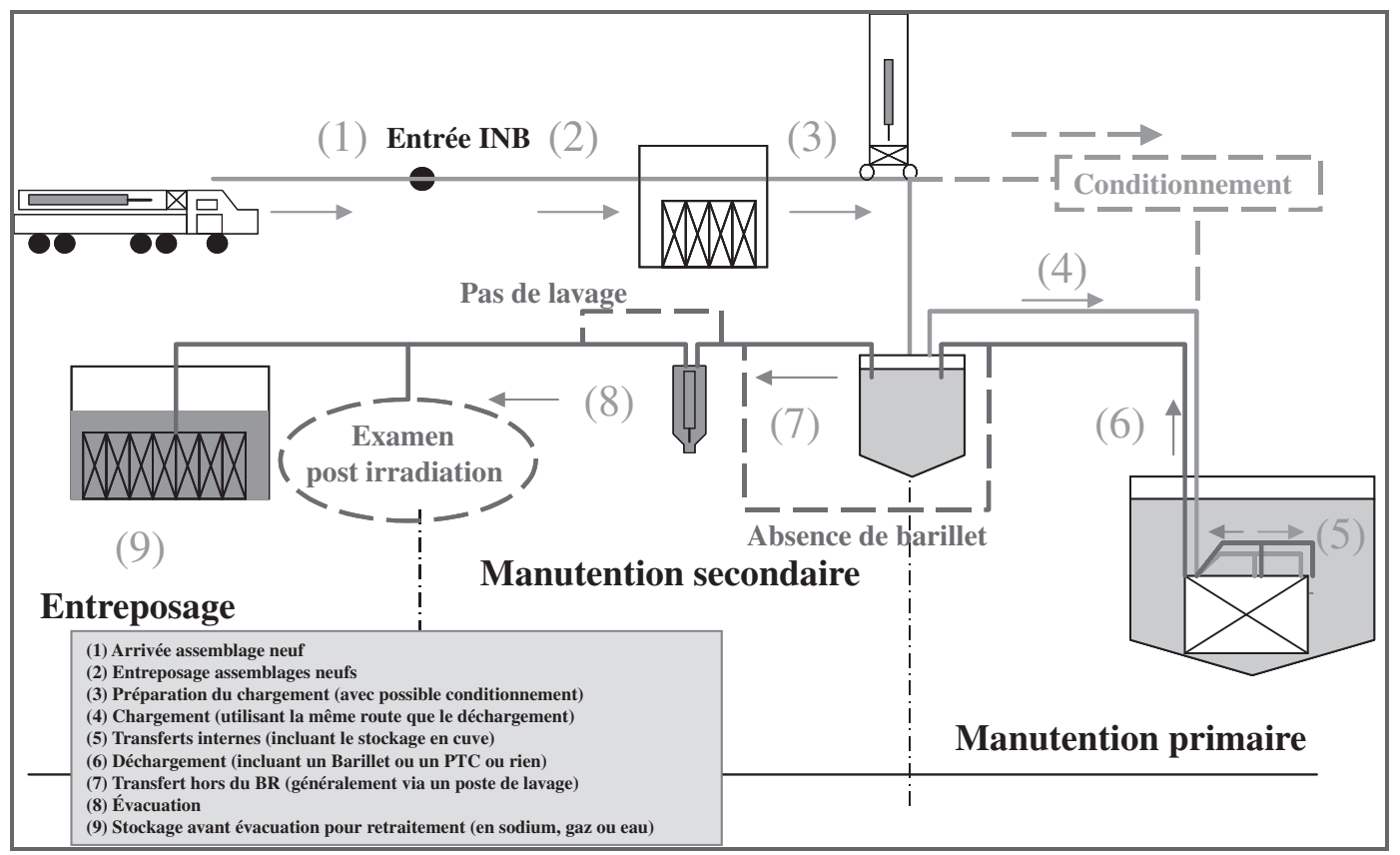

Fig. 1 General description of a FHS (including loading and unloading routes)

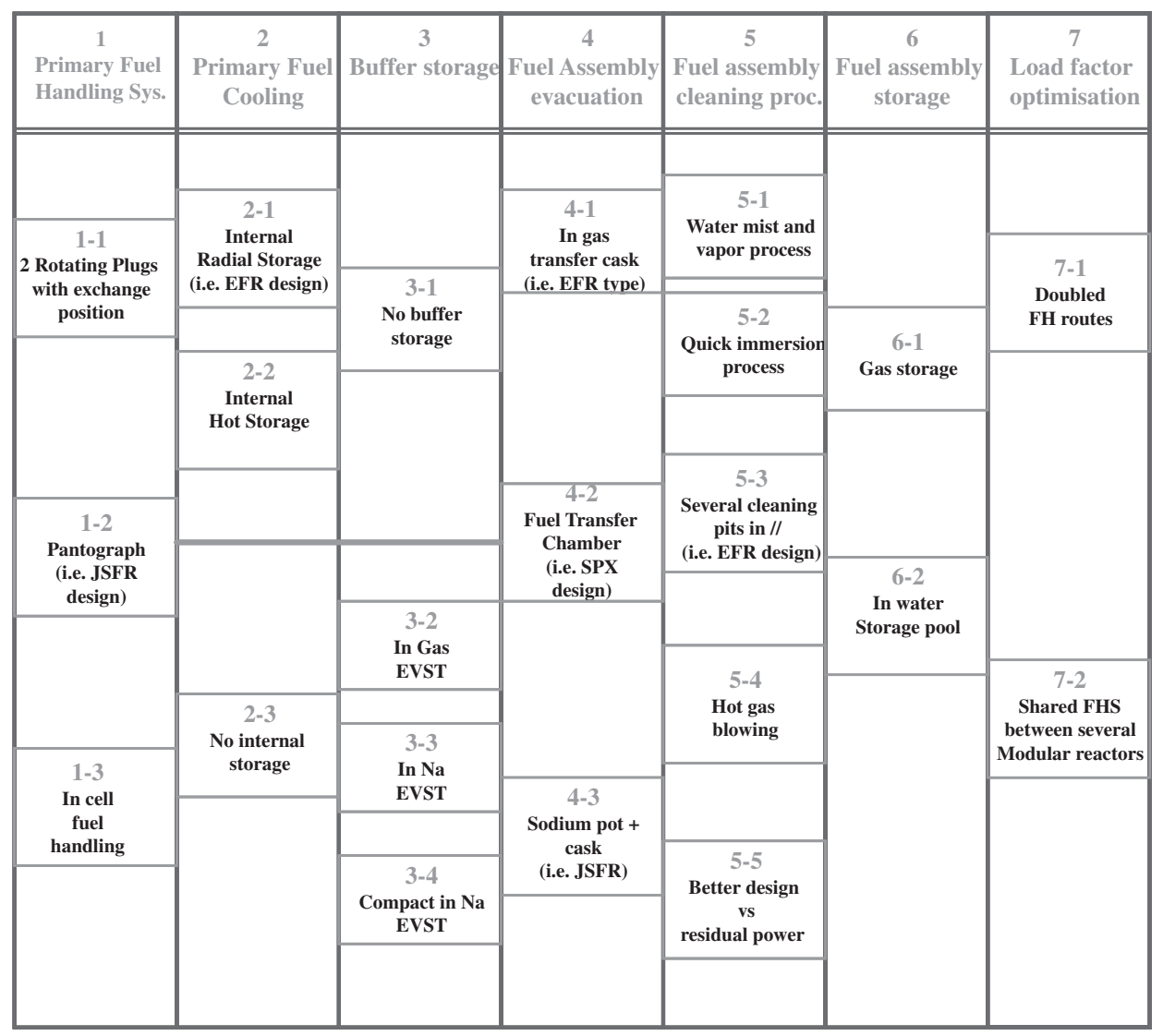

Fig. 2 List of different technical options for the FHS route

- Fresh fuel storage (2),

- Preparation of loading (with potential conditioning) (3),

- Loading (using the same handling route as the unloading) (4),

- Internal transfer (including the internal storage) (5),
- Unloading (can include an external vessel storage tank (EVST)) (6),

- Out of vessel transfer (7),

- Evacuation (can or cannot include a cleaning operation) (8), 


\section{CREYS-MALVILLE}

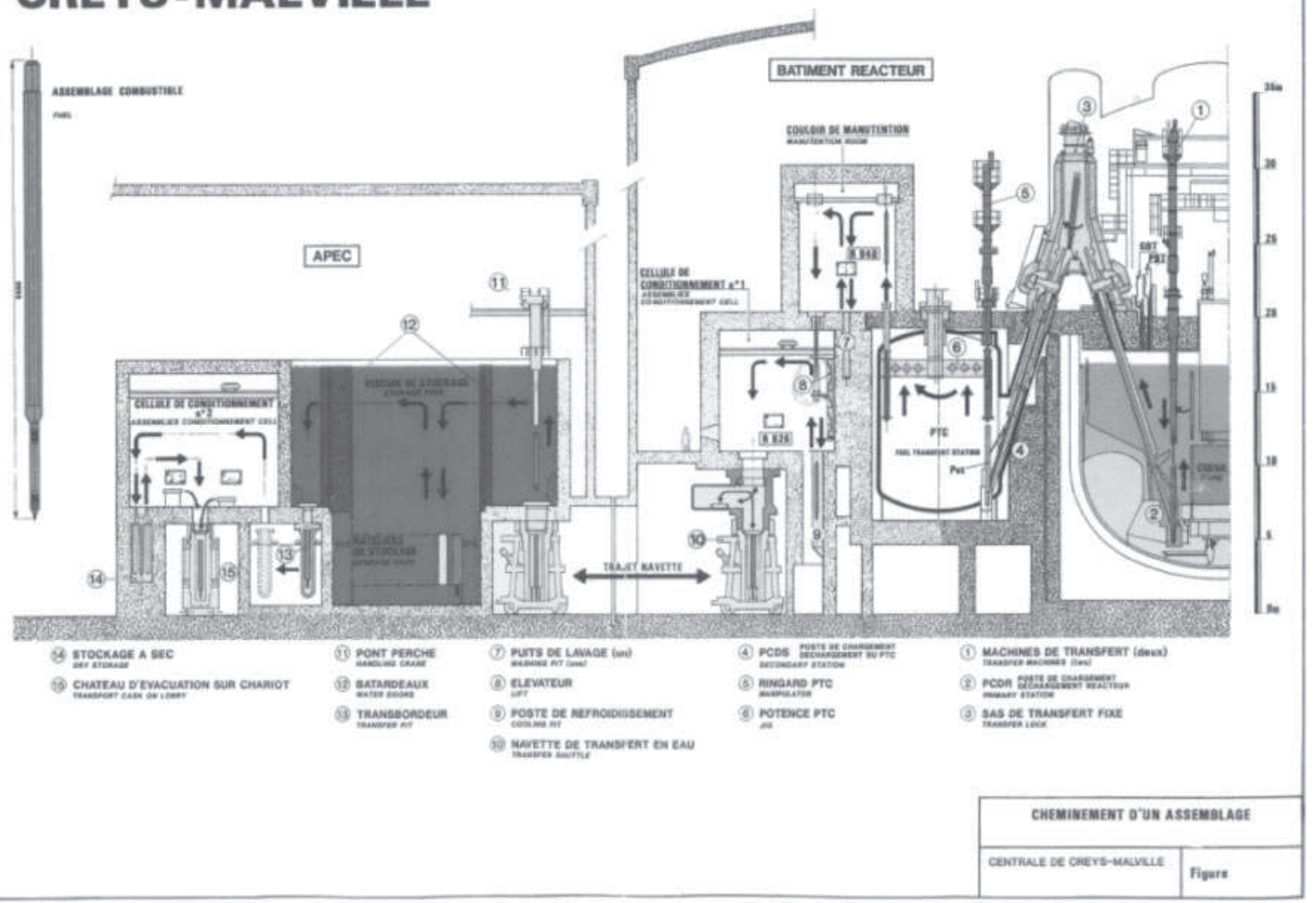

Fig. 3 SPX Fuel handling route after 1987

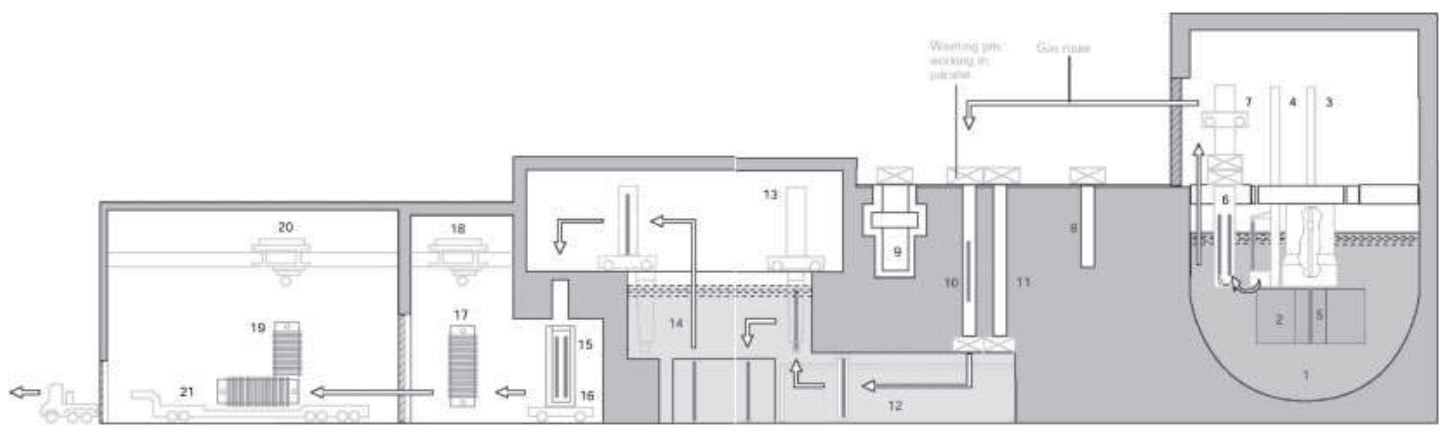

Fig. 4 EFR fuel handling route

- Storage for fuel cooling (in sodium, gas, or water) (9).

Based on this very general principle, several technological options can be chosen and have been applied to reactors (Fig. 1).

\section{Current Works on SFR French Project}

(Please refer to Figs. 5-11)

A fuel handling system for a FHS fuel handling route depends on assumptions considered for the whole project. For current French SFR studies on fuel handling systems, several assumptions/objectives have been taken into account:

- Reduce investments costs with improvement of IVFH compactness,
- Reduce impact of refueling operations on scheduled outages

$\circ$ Handling of assemblies with high residual power and decoupling primary and secondary handling,

- Be able to perform a fast whole-core discharge,

- Pooling of fuel handling systems on two units,

- Research on fuel assemblies cleaning process,

- Assessment of minor actinides impact on fuel handling systems,

- Assessment of alternative solutions for fuel handling in rupture with the current fast reactor design.

Those assumptions have led to the consideration of a sodium route for irradiated FAs with transfer of those FAs from the main vessel to the external storage tank in a sodium flask. 


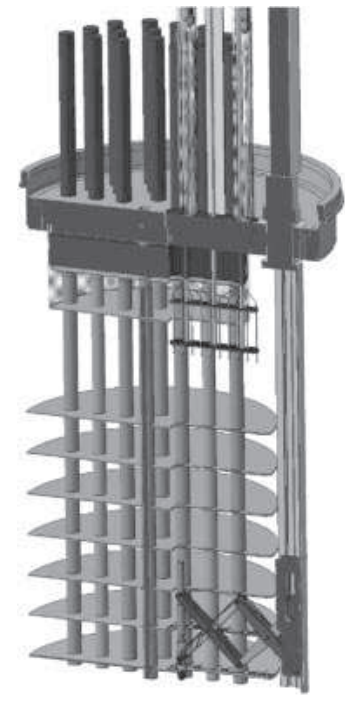

Fig. 5 Slitted ACS

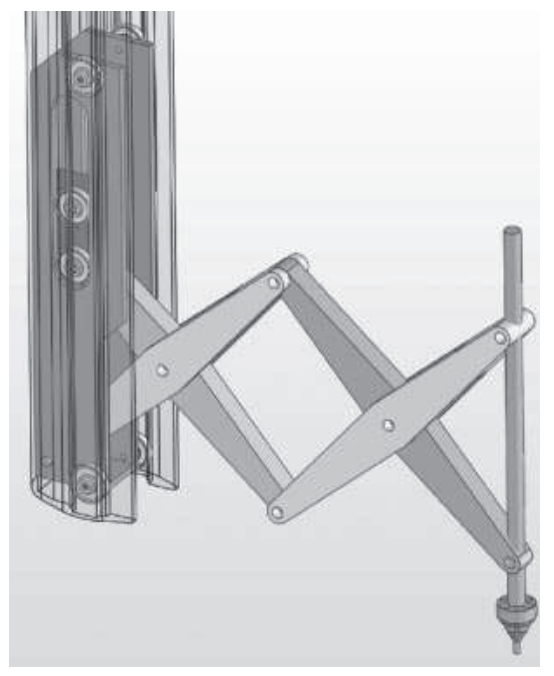

Fig. 6 Pantograph arm

\section{Reduce Investments Costs with Improvement of IVFH Compactness}

The in-vessel fuel handling system is included in the primary vessel system and provides the means to transfer subassemblies to and from all in-vessel positions during a reactor shutdown period. The estimation of rotating plug diameters is of high importance for the designer in order to propose a coherent image of the reactor block. An accurate evaluation is necessary to provide a description of all the parameters to be taken into account and the equations connecting all these terms. A specific tool has been developed whose objective is to find out the rotating plug diameters, the reactor vessel diameter, and the main sizing of the fixed arm charge machine. ${ }^{2)}$

This preliminary assessment of the primary fuel handling systems has compared different solutions to identify the best compactness.

From the viewpoints of primary vessel diameter optimisation and among the various evaluated concepts, two concepts were revealed to be the optimized options:

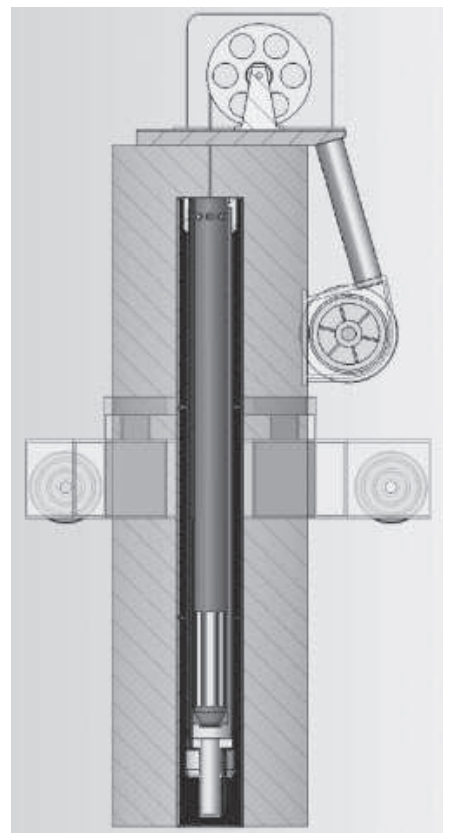

Fig. 7 Sodium flask

1) Two rotating plugs, a FACM in the LRP, and a DLCM in the SRP,

2) One rotating plug, a slitted ACS with pantograph-type FHM.

Following those analyses, some studies have been performed on the design of a pantograph arm. The principles of the arm are based on a double-scissor design. Some studies were dedicated to the design of the gripper and its functioning (more particularly the gripper actuation security system). A plug is set on the roof slab (inside the RP and the ACS) in case of jamming of the pantograph arm.

Monitoring of assemblies below ACS's slit is performed by a telescopic machine, which is raised during refueling operation. This machine is located on a plug inside the pantograph arm plug (used in case of rubble). It allows only the temperature monitoring of the assemblies (failed fuel location has no consequence on safety and will be performed by another system).

\section{Reduce Impact of Refueling Operations on Scheduled Outages}

In order to reduce the impact of refueling operations on scheduled outages, some tracks have been investigated with the following objectives:

- To handle FAs with high residual power with the help of a sodium flask,

- To reduce unavailability time with uncoupling of operations and by using an external vessel storage tank filled with sodium.

- To accelerate plug rotation and cask transfer and connections

The sodium flask candidate is based on SPX's A frame design (for sodium bucket design) and EFR's gas flask design (for design of the flask). This system allows handling of assemblies in sodium with residual power of about 30$40 \mathrm{~kW}$. 


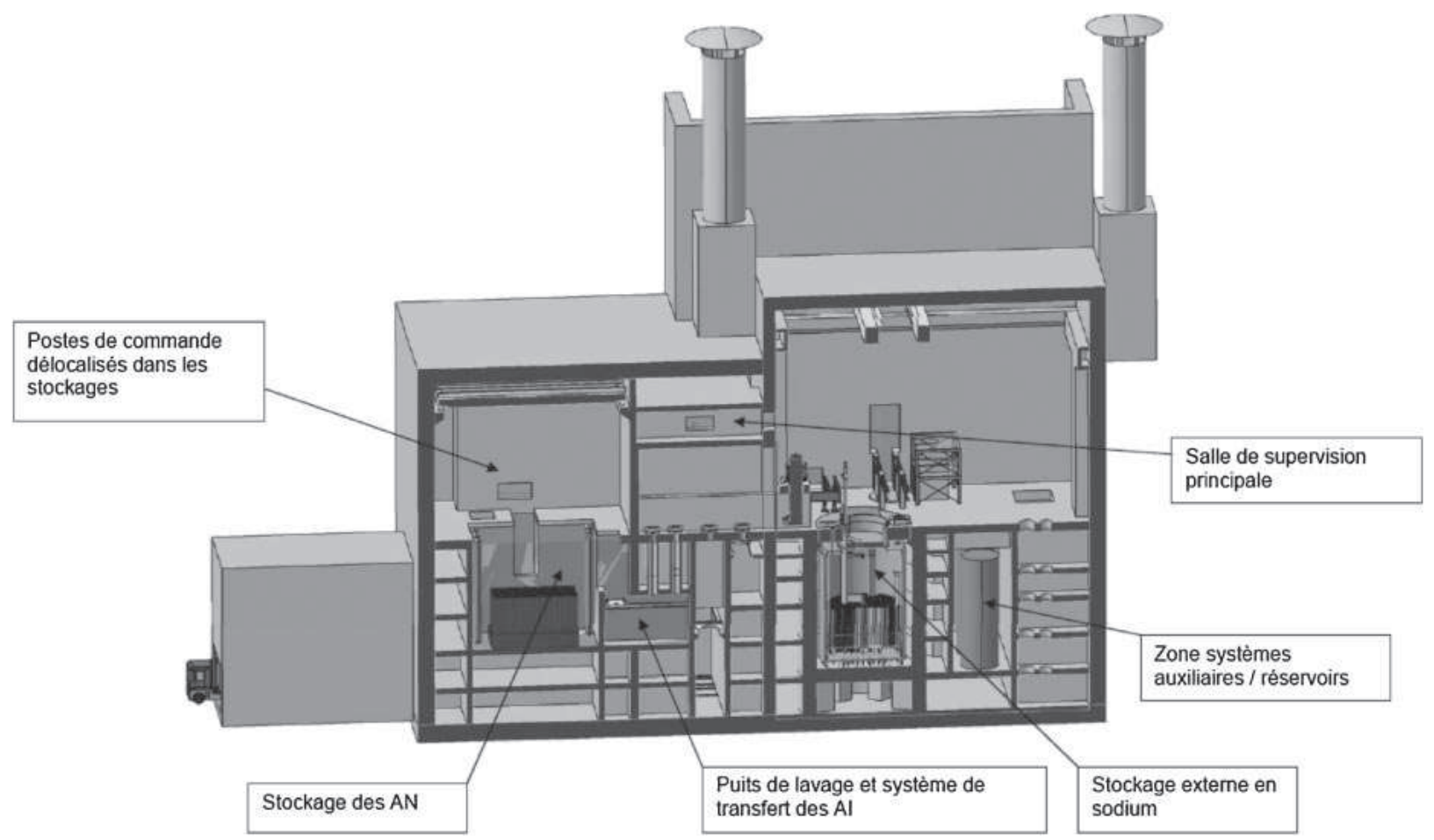

Fig. 8 External storage in sodium

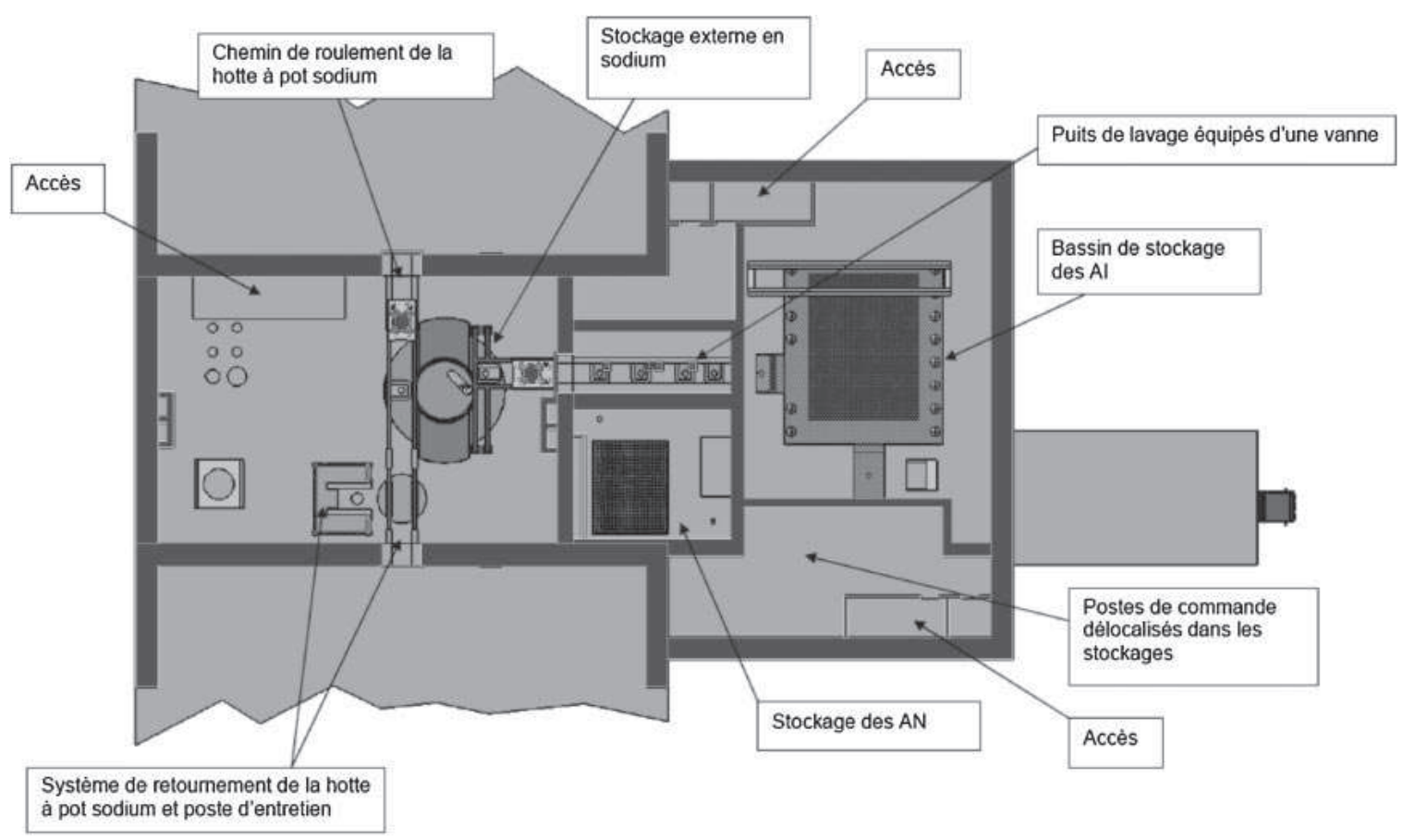

Fig. 9 Pooling of fuel handling equipment

The external storage is very compact ( $8 \mathrm{~m}$ for about 800 storage positions) and allows core management for two units and one whole core discharge (whole core discharge for the two units could be possible with some optimizations).

\section{Investigate Capacity of Whole-Core Discharge}

A whole-core discharge is an exceptional event which can be considered necessary in view of a comprehensive reactor inspection, for example in the case of doubt on a core sup- port structure. That is why speeds of all operations made during the core unloading are very important to reduce the costs for the plant operator on one hand and for the safety of reactors on the other hand.

Although not considered in the normal outage plans, the WCD would be an important operation that could direct design choices on fuel handling systems. For example, the handling of assemblies in gas is penalizing because it is necessary to wait for the decay of power for fuel assemblies 


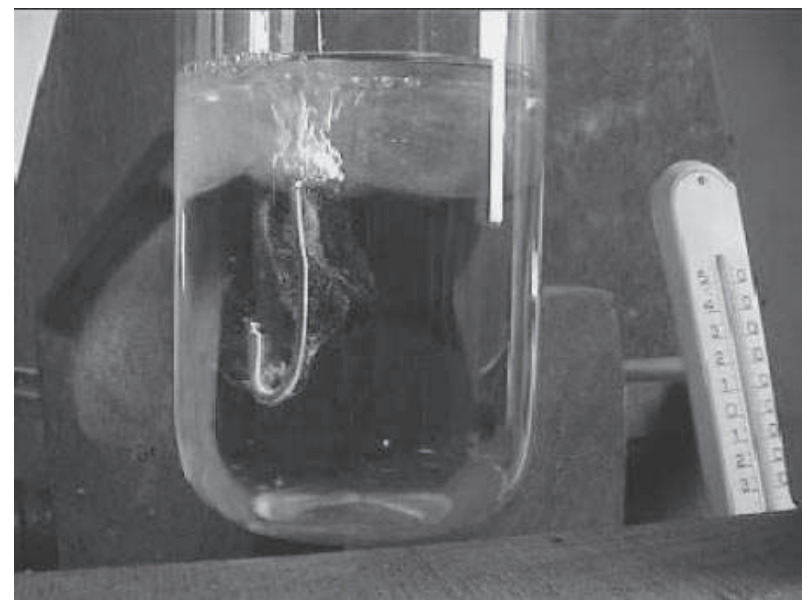

Fig. 10 Kinetic experiment of sodium in alkaline solution (the sodium bulk behaves like an "effervescent pill" in water)

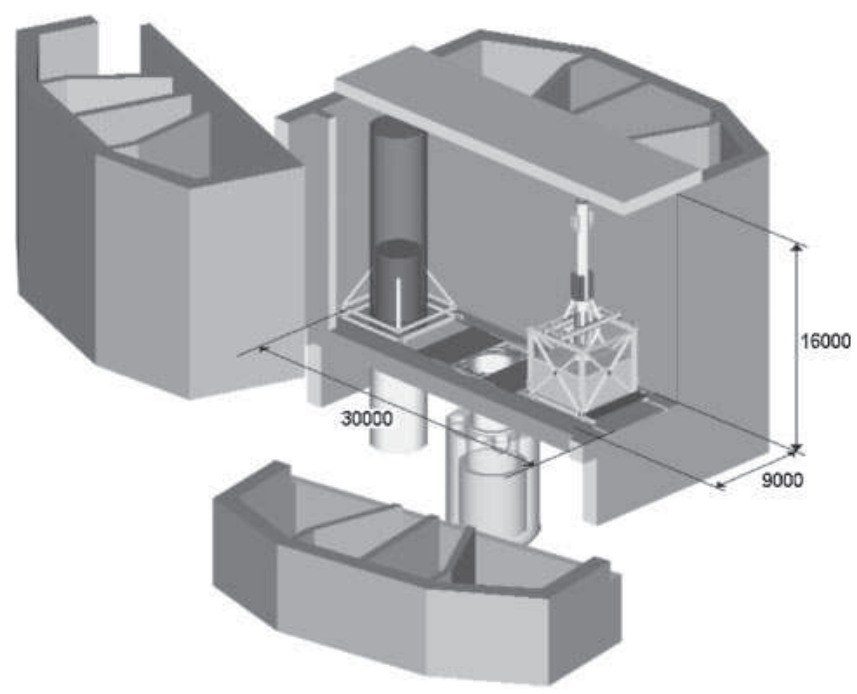

Fig. 11 eDf handling in a cell

(approximately 4 to 6 months) before being able to begin to unload assemblies from the primary vessel (maximum power for handling in gas: about $7.5 \mathrm{~kW}$ ). High-residualpower handling, with an in-sodium fuel handling system flask would allow handling of $30-40 \mathrm{~kW}$ residual power assemblies, thus allowing the discharge of the whole core in about 1 month.

An outcome of these studies is that a whole-core discharge is possible in about 1 month for the "sodium route" option and about 6 months for the "gas route option." The final decision will include other considerations, such as global economy and safety optimizations.

\section{Pooling of Fuel Handling Systems for Two Units}

Pooling of FHS has been investigated in the case of two units. The entire FHS equipment is installed in a dedicated building located between the two reactor buildings.

A sodium flask allows the transfer of assemblies from the primary vessel to the EVST. A gas flask allows the transfer of assemblies from the EVST to the cleaning equipment or the new fuel handling route.

\section{Research on Fuel Assembly Cleaning Process}

CEA is working on improving the cleaning process for fuel assemblies with a fast immersion in a saline solution or in a sodium hydroxide solution. The aim of this study is to allow the cleaning of FAs with a high residual power by reducing the time for cleaning. Some tests with different types of saline solutions have been performed in order to select the most suitable one. The purpose is to try to quickly and safely remove sodium with a concentrated alkaline solution instead of pure water to reduce sodium/water reactivity and still mastering the chemical reaction. It has been highlighted in several experiences and industrial processes that the use of concentrated sodium hydroxide can significantly lower the kinetics in comparison with a sodium/water reaction. This principle is for instance the basis of the NOAH process used to smoothly treat large amounts of primary sodium during the decommissioning phase of SFR, and this process has been successfully applied to RAPSODIE and PFR coolant reactors and will be now applied to the treatment of SPX primary and secondary sodium. ${ }^{3)}$

Last year, the first series of tests were done on a small amount of sodium in order to select the most appropriate salt (or sodium hydroxide) in connection with its optimal concentration. During the coming years, additional tests will be carried out to validate first conclusions under more representative conditions and to finish with a fuel mock-up on a representative scale.

For the cleaning of fuel assemblies, the first analysis and the investigation of the experimental feedback have revealed several improvements in that field, which will provide benefits on the load factor:

- Potential advantages on hot drainage with inert gas sweeping in order to reduce the residual $\mathrm{Na}$ inventory prior to cleaning,

- Integration of the experimental feedback of the PX and SPX cleaning processes in order to design an efficient improved cleaning pit,

- Validation on the industrial scale of a quick immersion cleaning process, which would greatly solve numerous difficulties in the design of the fuel handling route.

\section{Assessment of Minor Actinides Impacting on Fuel Handling Systems}

Fuel assemblies with minor actinides have different consequences following the recycling mode:

- The heterogeneous mode impacts all fuel handling systems because of the increase of residual power of fuel assemblies. Then it will be necessary to consider an in-sodium handling route (sodium flask) and, for some cases of MA recycling, an internal storage (in addition to the external one). Then, if an internal storage is quite necessary, that would be in contradiction to the requirement of a fast WCD.

- The homogeneous mode has less impact than the heterogeneous one and could be managed with SFR's reference fuel handling route.

- In both modes, the new fuel handling system will be impacted. Checking, inspecting, conditioning, and storing of new fuel assemblies will lead to remote devices because of high residual power and dose rate. 
7. Assesment of Alternative Solutions for Fuel Handling eDF has investigated a handling system in a cell (removal of ACS to allow access to all assemblies and then handling with a machine which realizes the link between the cell and the fuel building) with three ways of improvement:

- Simplify fuel handling systems,

- Improve access for inspection of internal structures,

- Avoid problems of core compaction by introducing the ACS in the core.

The handling of fuel assembly in gas with high residual power (about $25 \mathrm{~kW}$ ) and the avoidance of internal storage are expected. An improvement with an in-sodium handling is currently assessed. Many difficulties have to be considered:

- Sodium aerosol deposits in the cell,

- Maintenance of primary components (e.g., DHX) or components inside the cell,

- Duration of operating transients, before and after fuel handling campaign (e.g., ACS removal, preparation of the cell, and ACS requalification),

- Consequences on availability (e.g., maintenance operations, handling of failed assemblies, and ACS removal),

- Handling in gas with high residual power (short time before melting of the fuel in case of accident).

This study has revealed that this interesting solution would imply significant technological difficulties in terms of maintenance, handling, sodium quality control, and impact on the safety approach of the SFR concept. Therefore, this option is not pursued.

\section{Synthesis and Future Works}

Numerous solutions and options have been envisaged for the SFR fuel handling systems and routes. The design of this system must be considered at the early stage to take into account several parameters such as the following:

- The reactor design and the choice between loop or pool type reactor,

- The core design and its policy in terms of breeding ratio, minor actinides burning, etc.,

- The size of reactors: large-scale or modular medium-sizescale reactors, and their purpose: irradiation, prototype, or power,

- The targeted availability factor identified for the reactor: usually a value of $90 \%$ is given,

- The safety requirements.

One has to admit that no SFR built and drawn has the same fuel handling route. So, there is not one single solution but several FH routes that are most suitable for the concept and strategy chosen. Future works done in collaboration between CEA, AREVA, and EDF will progress on a more precise description of the FHS linked with a reactor concept, on the development of a code to calculate the load factor of every concept associated with a core strategy, and on the development of efficient, quick, and safe cleaning processes. Progress on these different $R \& D$ and engineering fields will orientate and provide a more accurate definition of a definitive fuel handling system for GEN IV French SFR.

\section{Nomenclature}

ACS: above core structure

$\mathrm{CB}$ : core barrel

CR: control rod

DHX: decay heat exchangers

DLCM: direct lift charge machine

EFR: European fast reactor

EVST: external-vessel storage tank

FA: fuel assembly

FACM: fixed-arm charge machine

FHM: fuel handling machine

FHS: fuel handling system

FTM: fuel transfer machine

IVFH: in-vessel fuel handling

IVTM: in-vessel transfer machine

LRP: large rotating plug

PFR: prototype fast reactor (Dounreay, UK)

PV: primary vessel

$\mathrm{RP}$ : rotating plug

$\mathrm{RV}$ : reactor vessel

SFR: sodium-cooled fast reactors

SMFR: small-modular fast reactor project

SRP: small rotating plug

SPX: Superphénix reactor

UIS: upper internal structure

WCD: whole-core discharge

\section{References}

1) P. Martin, J. Rouault, J.-P. Serpantie, D. Verwaerde, "French program towards a GEN IV sodium cooled fast reactor," ENC 2007, Brussels, Belgium, Sep. 16-20, 2007 (2007).

2) G. Prele, E. Sanseigne, M. Saez, G. Rodriguez, C. Majot, M. Chassignet, "Review and innovative technologies on fuel handling systems for sodium cooled fast reactors," Technical Mtg. on Fuel Handling Systems of Sodium Cooled Fast Reactors, Kalpakkam, Tamil Nadu, India, Nov. 24-27, 2008 (2008).

3) IAEA TECDOC, Operational and Decommissioning Experience with Fast Reactors, IAEA TECDOC-1534 (2007). 